\title{
Short term increase in low birth weight babies after Fukushima
}

\author{
Alfred Körblein(1)
}

\begin{abstract}
An analysis of low birth weight (LBW) births in ten contaminated prefectures of Japan, 1995-2018, finds a statistically significant increase in the LBW proportion in 2012-2013, but no increase after 2013. In the rest of Japan (37 prefectures), no increase in LBW births was found after the Fukushima accident.
\end{abstract}

Keywords: Fukushima, Low birth weight, Logistic regression, Trend analysis

In their recent article, Scherb et al. [1] investigated annual data of live births with low birth weight (LBW), 1995-2018, in selected regions of Japan before and after the Fukushima nuclear accident in March 2011. The trend of LBWproportion was analyzed employing logistic regression with a fourth-degree polynomial for the temporal trend, and allowing for a level shift from 2012 onward (variable cp, defined as cp = 1 in 2012-2018 and cp = 0 otherwise). Results were presented for Japan as a whole and three sub-areas: (1) five highly contaminated prefectures (Fukushima, Miyagi, Ibaraki, Tochigi, and Iwate), (2) five moderately contaminated prefectures (Yamagata, Saitama, Tokyo, Kanagawa, and Chiba), and (3) the rest of Japan (37 prefectures). In Japan as a whole, the level shift was statistically significant $(\mathrm{OR}=1.020, p$-value 0.025$)$. The effect was greater in area $1(\mathrm{OR}=1.055, p$-value 0.010$)$ than in area 2 $(\mathrm{OR}=0.021, p$-value 0.011$)$, and not statistically significant in area $3(\mathrm{OR}=1.015, p$-value 0.105$)$.

Since the numbers of live births and LBW births for all three areas were provided in Table 1 of [1], I was able to check the results. In my analysis I used logistic regression with program $\mathrm{R}$ (https://www.r-project.org/); the option family = quasibinomial was applied to adjust the variances for overdispersion. This means that F-tests were used instead of chi-square tests.

Correspondence: alfred.koerblein@gmx.de Nürnberg, Germany

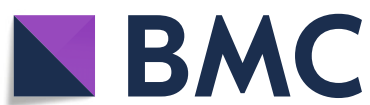

(0) The Author(s). 2020 Open Access This article is licensed under a Creative Commons Attribution 4.0 International License, which permits use, sharing, adaptation, distribution and reproduction in any medium or format, as long as you give appropriate credit to the original author(s) and the source, provide a link to the Creative Commons licence, and indicate if changes were made. The images or other third party material in this article are included in the article's Creative Commons licence, unless indicated otherwise in a credit line to the material. If material is not included in the article's Creative Commons licence and your intended use is not permitted by statutory regulation or exceeds the permitted use, you will need to obtain permission directly from the copyright holder. To view a copy of this licence, visit http://creativecommons.org/licenses/by/4.0/ The Creative Commons Public Domain Dedication waiver (http://creativecommons.org/publicdomain/zero/1.0/) applies to the data made available in this article, unless otherwise stated in a credit line to the data. 

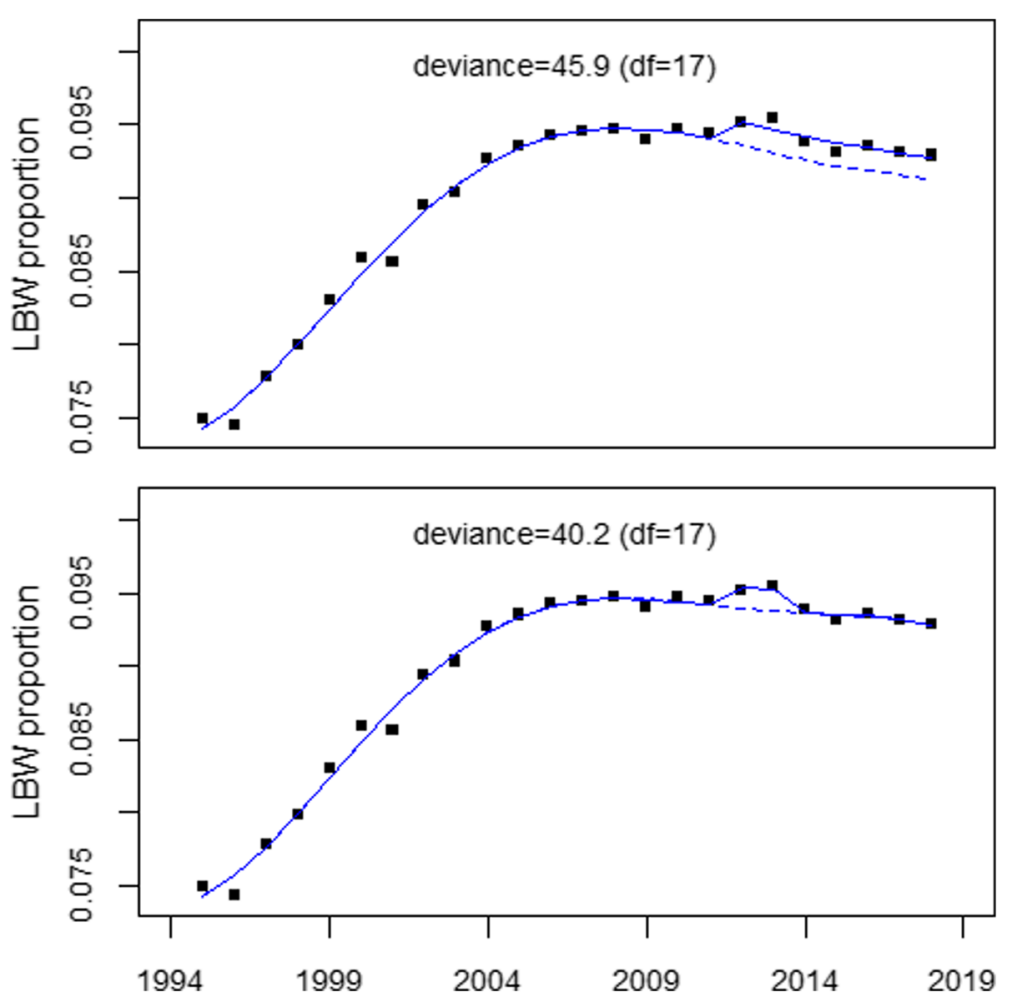

Fig. 1 Low birth weight proportions in the study region, 1995-2018, and results of regressions allowing for a level shift in 2012 (upper panel) and for an increase in 2012-2013 (lower panel)

$(\mathrm{df}=17)$, considerably smaller than deviance $=45.9(\mathrm{df}=$ 17) obtained with model 1. A similar regression for the control region with model 2 yielded OR $=0.998$ ( $p$-value 0.76). The trend of LBW proportions in the study region and the regression lines for the two competing models are shown in Fig. 1, upper and lower panel.

A considerable improvement of the fit was obtained when 2002 was chosen as the beginning of the study period. Logistic regression with a fourth-degree polynomial turned out to be the best choice for the long-term trend. The results were statistically significant for both regression model $1(\mathrm{OR}=1.019(1.003,1.035), p$-value $0.018)$ and model $2(\mathrm{OR}=1.015(1.005,1.025), p$-value 0.002 ), but model 2 fitted the data better (deviance $=7.5$, $\mathrm{df}=11)$ than model 1 (deviance $=11.3, \mathrm{df}=11)$. As the data showed no overdispersion, a chi-square test was applied for testing the significance of the odds ratios. The test for a possible level shift in addition to the effect in $2012-2013$ yielded OR $=1.00$ ( $p$-value 0.93$)$. Thus, the significant result for the shift in LBW proportion obtained with model 1 is driven by the peak in 2012-2013.

To conclude, my re-analysis of the data shows that there was an increase in LBW proportion in the first 2 years after Fukushima, but no increase after 2013. Thus, the claim by Scherb et al. that their result is evidence of a genetic radiation effect is challenged by the present analysis.
Acknowledgments

Not applicable.

Author's contributions

The author(s) read and approved the final manuscript.

Funding

The present study did not receive funding.

Availability of data and materials

Data was made available in reference [1].

Ethics approval and consent to participate Not applicable.

Consent for publication

Not applicable.

Competing interests

The author declares that he has no competing interests.

Received: 23 July 2020 Accepted: 31 August 2020

Published online: 25 November 2020

Reference

1. Scherb H, Hayashi K. Spatiotemporal association of low birth weight with Cs-137 deposition at the prefecture-level in Japan after the Fukushima nuclear power plant accidents: an analytical-ecologic epidemiological study. Environ Health. 2020;19:82. https://doi.org/10.1186/s12940-020-00630-w.

\section{Publisher's Note}

Springer Nature remains neutral with regard to jurisdictional claims in published maps and institutional affiliations. 